\title{
Biological activities (antioxidant and antimicrobial activity) of the aqueous extracts and essential oil of Ammoides verticillata (Nounkha)
}

\author{
Ramdane MOHAMED SAID*, Nabahat BENMANSOUR \\ Department of Biology and Cellular Physiology, Faculty SNV, University Blida 1, Algeria \\ *corresponding author: rmohamedsaid@yahoo.fr \\ Bulletin UASVM Animal Science and Biotechnologies 75(2)/ 2018 \\ Print ISSN 1843-5262; Electronic ISSN 1843-536X \\ DOI:10.15835/buasvmcn-asb: 2018.0006
}

\begin{abstract}
The phytochemical review conducted on the aerial part Ammoides verticillata has revealed the presence of six chemical families: flavonoids, tannins; gallic tannins, anthocyanins and the coumarins, cateichic tannins. The aqueous extract of the Ammoides verticillata could bring back the stable free radical 2,2-diphenyl-1-picrylhydrazyl (DPPH) to the yellow-colored diphenylpicrylhydrazine with an IC50 of $0.020 \mathrm{mg} \cdot \mathrm{mL}^{-1}$. It is gifted with antioxidant activity, however it was less effective than vitamin C $\left(0.001 \mathrm{~mL}^{-1}\right)$. The essential oil of the Ammoides verticillata has presented a strong antimicrobial activity against Gram negatif germs targets of original clinical action: $E$. coli (ESBL) (37 mm), E. coli (39.5 mm), Klebsiella pneumoniae $(36.5 \mathrm{~mm})$ and especially with the yeast: Candida albicans ATCC 10231 (47 mm) and Saccharomyces cerevisie ATCC (42 mm), which are highly sensitive to the oil inhibitory action. However, the oil has presented a low activity against the bacteria P. aeruginosa $(12.5 \mathrm{~mm})$.
\end{abstract}

Keywords: Ammoides verticillata, essential oil, aqueous extract, organic activities.

\section{INTRODUCTION}

The aromatic plants are not only endowed perfuming and culinary qualities, but also with various medicinal properties due to the different active ingredients they contain: alkaloids, flavonoids, tannins, saponins and essential oils (Tefiani et al., 2016).

The Apiaceae family is one of the richest in essential oils. It includes vegetables (carrot, fennel, celery) and condiments (caraway, coriander, cumin, parsley) (Kambouche, 2000). The present study of Ammoides verticillata(Fig.1) has had for objectives:

- The chemical components identification of the aqueous extract and the evaluation of its antioxidant activity with respect to free radicals using the DPPH method;

- The essential oils extraction and the evaluation of their antimicrobial activity.

\section{I- MATERIALS AND METHODS}

\section{I-1 Biological material}

Plant material: The work focused on the plant Ammoides verticillata, collected at the Terny station (south of Tlemcen, Algeria) (Fig.1).

Bacteria: The antimicrobial potency of the essential oils of Ammoides verticillata has been tested using 2 reference strains and bacterial strains of clinical origin isolated from three different pathological products (urine, pus and stool).

Animals: The anti-inflammatory activity of Ammoides vertivillata focused on 18 Albino mice, NMRI race (Naval Medical Research Institute), male and female, weight ranging from 19 to $23 \mathrm{~g}$. These mice were fed with granules and tap water. The hosting conditions meeted the local standard temperature $\left(20-24^{\circ} \mathrm{C}\right.$ ), photoperiod (10 hours per day), humidity rate $(\approx 50 \%)$. 


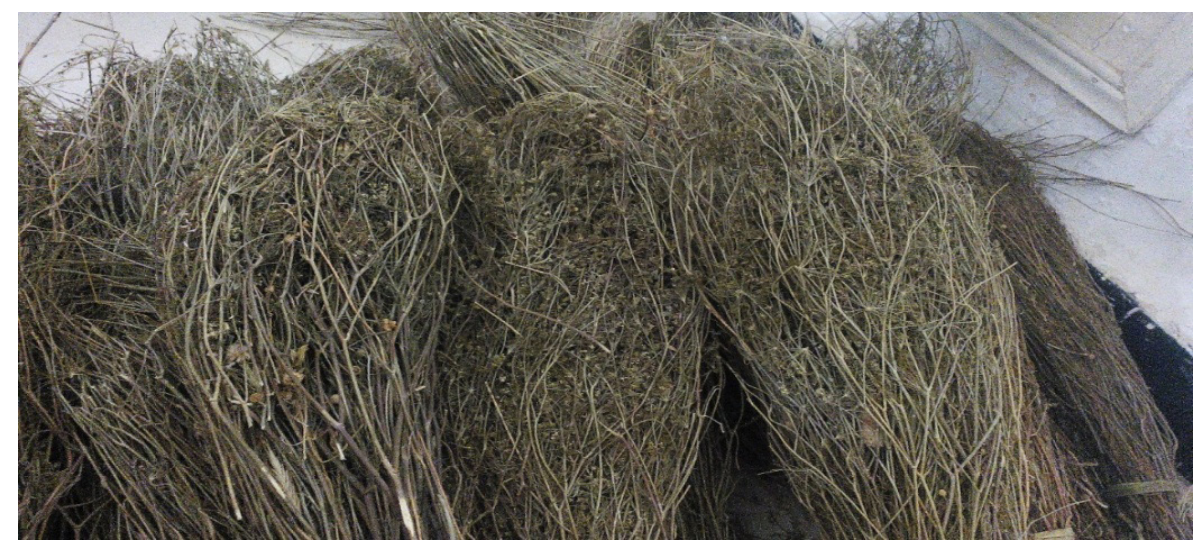

Figure 1. Original photo of the dry plant in bouque(Ammoides verticillata) (2016).

\section{I-2- METHODS}

Samples collect of Ammoides verticillata: In the selected plots, all the feet of healthy, wellsupplied and ungrazed Ammoides verticillata were cut. Their number inside a surface of $1 \mathrm{~m}^{2}$ varied from 1 to 3 . A sample of 100 feet on $10 \times 10 \mathrm{~m}^{2}$ was collected during a month, then the samples were placed in well-ventilated bags and spread on paper in the shade and protected from moisture at room temperature until they become completely dry.

Extraction of essentiel oil from Ammoides verticillata: In this study, the extraction method used is hydrodistillation in Clevenger type apparatus. This method is interesting on the one hand for its optimality in the essentiel oil yield and on the other hand for advantages in several parameters such as the plant material quantity and state, the quantity of water introduced or the duration of extraction.

Experimental protocol: A well-weighed cup of the dry and possibly milled plant is introduced into a one liter glass flask with 3 necks, impregnated with distilled water, placed over a balloon heater and surmounted by a glass column, connected to a refrigerant which communicates directly to a separating funnel for the distillate recovery. The bulb is connected to the balloon by a plastic pipe which allows the return of evaporated and condensed water to the balloon. The average duration of extraction is about 3 hours.

After decantation, the essential oil is recovered by aspiration using a Pasteur pipette and stored in glass tubes, hermetically closed, in the dark and at a temperature between 4 and $6^{\circ} \mathrm{C}$.
Performance calculation: The essential oil yield is defined as the ratio of the obtained mass of essential oil by the dry mass of the treated plant material. The yield, expressed as a percentage, is calculated by the following formula:

$$
\mathrm{Rd}=(\mathrm{m} / \mathrm{m}) \times 100
$$

$\mathrm{Rd}$ is the essential oil yield expressed as a percent, $m$ the essential oil mass in grams and $m_{0}$ the mass of the dry vegetable matter in grams.

\section{A-Preparation of aqueous extract}

The preparation of the $10 \%$ aqueous extract of plant is carried out by adding $10 \mathrm{~g}$ of powder of the aerial part to $100 \mathrm{~mL}$ boiled distilled water, then left for 30 min in infusion with stirring from time to time. The aqueous extract obtained is then centrifuged at $1000 \mathrm{rpm}$ for $10 \mathrm{~min}$ to get rid of plant debris and filtered on Wattman $n^{\circ} 3$ filter paper. The filtrate is finally put in small glass vials.

\section{Phytochemical screening}

According to Harborne (1983), depending on turbidity, medium color and precipitate intensity, the phytochemical results are classified as follows: very positive reaction $(+++)$, moderately positive reaction $(++)$, shady reaction $(+)$, negative reaction $(-)$.

\section{A-Flavonoids}

The presence or absence of flavonoids in an extract can be demonstrated by a simple and rapid test: the magnesium test. A few drops of concentrated $\mathrm{HCl}(2 \mathrm{~N})$ and $0.5 \mathrm{~g}$ of $\mathrm{Mg}$ are added in $5 \mathrm{~mL}$ of the methanolic extract. This is allowed 
to act for $3 \mathrm{~min}$. Orange or red color appearance indicates a flavonoids presence.

\section{B-Tannins}

One $\mathrm{mL}$ of $10 \%$ aqueous extract is mixed with $1 \mathrm{~mL}$ of distilled water and 1 to 2 drops of $10 \%$ diluted $\mathrm{FeCl}_{3}$ solution. The test is considered positive by dark green or blue-green color appearance.

\section{C-Galenic tannins}

Add $2 \mathrm{~g}$ of sodium acetate to $15 \mathrm{~mL}$ of the infused, then few drops of a $5 \% \mathrm{FeCl}_{3}$. A dark blue color indicates a gall tannins presence.

\section{D-Catechetical tannins}

Add $7 \mathrm{~mL}$ of Stiasny reagent to $15 \mathrm{~mL}$ of the infused. A red color indicates a catechetical tannins presence.

\section{E-Free quinones}

Add $2 \mathrm{~g}$ of the powder to $2 \mathrm{~mL}$ of hydrochloric acid (97\%), leave in contact for 3 hours in chloroform. After filtration, add few drops of ammonia $(0.5 \%)$. The presence of free quinones is shown by a red coloring.

\section{F-Coumarins}

Put $2 \mathrm{~g}$ of powder in $20 \mathrm{~mL}$ of absolute ethanol. Boil for 15 min under reflux then cool and filter. Add 10 drops of $\mathrm{KOH}$ and a few drops of concentrated $\mathrm{HCl}(37 \%)$, diluted at $10 \%$ in 2 to $3 \mathrm{~mL}$ of filtrate diluted in ethanol (10\%). The test is considered positive by the appearance of a red color.

Principle of evaluation of the antioxidant activity of aqueous extracts (in vitro)

The antioxidant activity of Artemisia judaïca L. was highlighted with the DPPH method (2,2-diphenyl-1-picrylhydrazyl). The antioxidant capacity is measured using more stable free radicals. The 1,1-diphenyl-2-picrylhydrazyl radical (DPPH) is a very stable free radical in the crystalline state and in solution, of violet coloring. By this method, it is considered that the antioxidant activity is none other than the ability of antioxidants to act as a scavenger of free radicals. They act by transferring a hydrogen atom, which leads to the DPPH disappearance during the reaction and to a color change (yellow) in the initial solution (Boulanouar et al., 2013).

$$
\begin{aligned}
& \text { Percentage of antioxidant activity }=\mathrm{I} \% \\
& =\left[\left(\text { Absorbance }_{\text {control }}-\text { Absorbance }_{\text {sample }}\right) /\right.
\end{aligned}
$$$$
\text { (Absorbance }{ }_{\text {control }} \text { )] } \mathrm{x} 100 .
$$

\section{A-IC50}

IC50 (50\% inhibitory concentration), also called EC50 (efficient concentration 50), is the concentration of the tested sample, required to reduce $50 \%$ of the DPPH radical. It is inversely related to the antioxidant capacity. The IC50 are graphically determined by percent inhibition based on different concentrations of the tested extracts (El Ouariachi et al., 2011).

\section{Evaluation of antimicrobial activity}

\section{A-Preparation of the inoculum}

- the bacterial inoculum

A well isolated colony of the germ to be studied is taken from a pure bacterial culture in a Petri dish, then introduced into a hemolysis tube containing $1 \mathrm{~mL}$ of nutrient broth. From the suspension obtained, dilutions are made in order to obtain a dense culture: density equivalent to 0.5 Mac Farland standard $\left(108 \mathrm{CFU}_{\mathrm{mL}}^{-1}\right.$, the suspension containing from $10^{6}$ to $10^{7}$ bacteria. $\mathrm{mL}^{-1}$ ).

\section{- yeast inoculum}

From a pure culture, a well isolated colony of the yeast is collected and then seeded on a liquid Sabouraud medium incubated at $30^{\circ} \mathrm{C}$ for $18 \mathrm{~h}$. Dilutions are then carried out until obtention of $10^{5}$ cells. $\mathrm{mL}^{-1}$. The number of cells is counted with the Mallassez cell.

\section{B-Confrontation essential oil-bacteria and essential oil-yeast \\ - Flood seeding}

One $\mathrm{mL}$ of the bacterial inoculum or yeast is deposited then spread on Muëller-Hinton or Sabouraud medium. Excess liquid is aspirated and the can is allowed to dry for $15 \mathrm{~min}$ at $35^{\circ} \mathrm{C}$.

- Deposition of disks impregnated with essential oil and incubation

Three to five sterile discs of Whatman $n^{\circ} 3$ paper, $6 \mathrm{~mm}$ in diameter, are impregnated with $2.5 \mu \mathrm{L}$ of different essential oil extracts from plant sites. They are deposited at the surface of MüellerHinton medium or Sabouraud agar. The disks are arranged in such a way that the inhibition zones do not overlap.

After the essential oil diffusion into the medium for $15 \mathrm{~min}$ at $30^{\circ} \mathrm{C}$, the dishes are incubated at $37^{\circ} \mathrm{C}$ for the bacteria and at $30^{\circ} \mathrm{C}$ for the yeast. The reading is carried out after $24 \mathrm{~h}$ of incubation for the bacteria and $48 \mathrm{~h}$ for the yeast by measuring the inhibition zone diameter of the target germ. 
The inhibition zone diameters (mm) are measured, including the disks diameters. These measurements are transcribed into different symbols proportional to the activity (Abdelouahid and Bekhchi, 2004). All tests were performed in triplicate. Imipenem $(10 \mu \mathrm{g})$ and Vancomycin (30 $\mu \mathrm{g}$ ) served as positive controls.

\section{II-RESULTS}

\section{II-1-Organoleptic characteristics}

The organoleptic characteristics of the Ammoides verticillata essential oil obtained by hydro distillation are liquid appearance, light yellow color and characterized by a strong pungent odor.

\section{II-2- Essential oils extraction by hydro distillation}

II-2-1-Determination of the vegetable quantity necessary for extraction

The yield of essential oil was calculated according to the dry plant matter of the aerial part of the plant. The results have shown a yield of essential oil which varies depending on the plant material mass. It has reached its maximum $(1.6 \%)$ with $100 \mathrm{~g}$ of the dry plant. It has rapidly decreased to about $1.4 \%$ for $200 \mathrm{~g}$ of the dry plant and then continued to decrease more slowly.

These variations in the yield are probably related to the degree of unsuitable settlement (insufficient or excessive) that forces steam to take preferential paths.

As a result, in some places, the steam does not come into contact with the plant material with consequently decreasing in the yield. The ideal weight for the essential oils extraction seems to be $100 \mathrm{~g}$ of vegetable matter.

The Ammoides verticillata essential oil was obtained with a relatively average yield $(1.60 \%$ on a dry weight basis). Some differences in yield were observed in samples of Ammoides verticillata from different origins: Algeria, 4.41\% (Kambouche and Abed, 2003), Morocco, 2\% (El Ouariachi et al., 2011).

\section{II-3-Phytochemical Screening}

Phytochemical screening allowed us to highlight the presence of secondary metabolites in the plant tissues. Phytochemical examination carried out on the aerial part of Ammoides verticillata revealed the presence of 6 chemical families: flavonoids, tannins, gallic tannins, catechin tannins, anthocyanins and coumarins
(Boulanouar et al., 2013). However, there is a lack of free quinones in our extract. Flavonoids and gallic tannins were present in larger quantities compared to other chemical families.

These chemical families, detected in our study, confirm earlier work of Toubal et al. (2012) on the phytochemical tests of the aqueous extract of Ammoides verticillata which certified the presence of tannins, anthocyanins, coumarins and especially flavonoids in significant quantities. It is noted that this plant contains a high amount of tannins and confirms works of Oumessaad et al. (2011). In addition, the existence of tannins explains the woody form of this shrub.

\section{II-4-Antioxidant activity}

The antioxidant activity is dependent on the hydrogen atom mobility of the hydroxyl group of the essential oil phenolic compounds. In the presence of a free radical DPPH, the $\mathrm{H}$ atom is transferred on the latter thus transformed into a stable molecule DPPH, this causes a decrease in the concentration of the free radical and also the absorbance during the reaction time to depletion of the hydrogen donor antioxidant capacity.

The DPPH has a dark purple color but when trapped by antioxidant substances its color turns to pale yellow. The turn towards this coloring and its intensity depends on the nature, the concentration and the potency of the anti-radical substance.

\section{bition}

II-4-1-Determination of percentage inhi-

The test results have shown that the inhibition percentage of free radical increases with the concentration increase for either the control product of ascorbic acid (vitamin $\mathrm{C}$ ) or aqueous extract of Ammoides verticillata. It is noted that the antioxidant effectiveness increases with the the aqueous extract concentration. However, the free radical inhibition percentage for the extract is slightly lower than that of ascorbic acid for all the used concentrations. At the concentration of $100 \mathrm{mg} \cdot \mathrm{mL}^{-1}$, the aqueous extract of Ammoides verticillata revealed a percentage inhibition of DPPH at $93.58 \%$ while that of vitamin C was $94.77 \%$.

\section{II-4-2- Determination of IC50}

IC50 is inversely related to the antioxidant capacity of a compound. It expresses the amount of antioxidant required to decrease the free radical concentration by $50 \%$. The lower the IC50 value, 
Table 1. Transcription of Inhibition Diameter (ID) values

\begin{tabular}{ccc}
\hline Inhibition & Transcription & Sensibility \\
\hline $\mathrm{D}<8 \mathrm{~mm}$ & - & Resistant \\
\hline $9 \mathrm{~mm} \leq \mathrm{D} \leq 14 \mathrm{~mm}$ & + & Sensitive \\
\hline $15 \mathrm{~mm} \leq \mathrm{D} \leq 19 \mathrm{~mm}$ & ++ & Quiet sensitive \\
\hline $\mathrm{D} \geq 20 \mathrm{~mm}$ & +++ & Very sensitive \\
\hline
\end{tabular}

the greater the antioxidant activity of a compound. The aqueous extract of Ammoides verticillata could bring the stable free radical 2,2-diphenyl1-picrylhydrazyl (DPPH) to yellow-colored diphenylpicrylhydrazine with an IC50 at 0.020 mg.mL ${ }^{-1}$. It exhibits lower antioxidant activity than vitamin $\mathrm{C}\left(0.001 \mathrm{~mL}^{-1}\right)$.

According to the results found, it appears that the aqueous extract of Ammoides verticillata has an antioxidant activity, but less effective than that of vitamin C. Moreover, by comparing the IC50 of our extract $\left(0.020 \mathrm{mg} \cdot \mathrm{mL}^{-1}\right)$ with that of essential oil of Ammoides verticillata (0.10 mg.mL ${ }^{-1}$ ) studied by Merzougui and Tadj (2012), our extract is unveiled with more antioxidant power than the essential oil. However, some authors have detected a remarkable antioxidant effect (IC50 $=0.007 \mathrm{mg} . \mathrm{mL}^{-1}$ ) in organic extracts of another species of the same genus Ammoides atlantica. However these IC50 results were performed with other methods of antioxidant activity. On the other hand, it turns out that this antioxidant activity is related to phenolic compounds presence in extracts and essential oils. They are known as potent antioxidants and as free radical reducers (Valnet, 2010). In addition, phenolic compounds are very important components in the extracts and their free radical scavenging ability is due to their hydroxyl groups.

\section{II-5-Antimicrobial activity}

The antibiogram is an effective biological method to directly determine the antimicrobial effect of the Ammoides verticillata essential oil on the micro organisms tested. For this, the sensitivity of the strains tested was estimated by measuring the inhibition zones diameters of in both perpendicular directions around the disks impregnated with the Ammoides verticillata essential oil. The inhibition zones diameters (mm) were measured, including the disks diameter. These measurements were transcribed in different symbols proportional to the activity. All tests were performed in triplicate.

According to several authors, essential oils are considered active if they produce inhibition diameters equal or greater than $20 \mathrm{~mm}$. As a result, the Ammoides verticillata essential oil has a strong antibacterial action against the Gram- target germs of clinical origin: E. coli (ESBL), E. coli and Klebsiella pneumonia which are highly sensitive to the oil inhibitory action with respective inhibition diameters: 37, 39.5 and $36.5 \mathrm{~mm}$. However, the oil is endowed with a lower activity against the bacterium $P$. aeruginosa (12.5 mm).

The Ammoides verticillata essential oil has also a strong activity against Gram+ bacteria: Staphylococcus aureus, Faecal Streptococci and Bacillus spp. which are extremely sensitive to the oil inhibiting action with 25\% diameters respective inhibitions: 39,33 and $34 \mathrm{~mm}$. The yeasts Candida albicans ATCC 10231 and Saccharomyces cerevisia ATCC are also very sensitive towards the very important inhibiting power of the Ammoides verticillata essential oil since they are inhibited with the respective inhibition diameters: 47 and $42 \mathrm{~mm}$. The present study have shown that the antibacterial activity of the volatile oil was more pronounced against Gram- bacteria than P. aeruginosa. This result is in agreement with numerous studies carried out on other plant species. This bacterium is also known for its resistance to many antibiotics, it is an opportunistic pathogen in immunocompromised persons where it is responsible in frequent and serious nosocomial infections in patients (Caillet and Lacroix, 2007).

The antibacterial activity of essential oils as well as their mode of action are directly influenced by the nature and the proportion of 
the constituents entering in their composition. The majority compounds are often responsible for the observed antibacterial activity; thus, the important inhibitory power of the Ammoides verticillata essential oil against the target germs could be attributed to the high content of tymol and carvacrol already cited by several works. These phenolic aromatic compounds, in fact, are known to their antimicrobial properties.

The antimicrobial activity of the essential oil can be explained by the lipophilic nature of the monoterpene contained therein. Monoterpene act by disrupting the microbial cytoplasmic membrane, which causes a destabilization of the structure and an increase in membrane permeability. These changes result in ion leakage and intracellular compounds. If the material loss is too important to the bacterial survival, this causes cell death. The Ammoides verticillata essential oil has a strong antibacterial activity against the bacteria of clinical origin and especially with respect to the yeasts. Similar observations about extracts and essential oils from the same species have also been reported by several researchers (Bakchiche et al., 2013).

\section{CONCLUSION}

The main idea of our study was to extract Ammoidesverticillata essential oil(said Nounkha) from the Terny region (wilaya de Tlemcen), to determine its physicochemical properties and to evaluate in vitro its antimicrobial properties towards different microbial species, as well as its antioxidant activity. From the literature review, it appears that this plant, belonging to the family of Apiaceae carries many plant synonyms. Hydrodistillation, the method of choice for the essential oils extraction, allowed us to show that the Nounkha plant is rich in essence. The estimated yield is $1.6 \%$. Phytochemical examination carried out on the aerial part of Ammoides verticillata revealed the presence of chemical compounds especially flavonoids and tannins. The biological activity tests, carried out in vitro, allowed to assess the presence of important inhibitions zones, indicating that the essential oil has a biological activity on all the microorganisms tested. These experiments have revealed a high sensitivity of yeasts Candida albicans ATCC 10231 and Saccharomyces cerevisia ATCC opposite gasoline compared to other germs. In addition, the results of the evaluation of the antioxidant activity have revealed that the Ammoides verticilata essence has a high antioxidant power. Finally, it is recommended for this plant species the study of the chemical composition variability by the joint implementation of chromatographic techniques (TLC, HPLC and CG/MS) and spectroscopic methods, taking into account the the plant age, and if possible, the time and place of harvest. This will allow to observe the different changes in terms of quality and quantity of essential oils in order to estimate under what conditions or in what period these essential oils could have an interesting activity.

Acknowledgments. This research did not receive any specific grant from funding agencies in the public, commercial, or not-for-profit sectors.

\section{REFERENCES}

1. Abdelouahid DE, Bekhchi C (2004). Antimicrobial essential oil power.

2. Bakchiche B, Gherib A, Aazza S, Gago C, Miguel MG (2013). Antioxidant activities of eight Algerian plant extracts and two essential oils. Industrial Crops and Products, 46: 8596.

3. Boulanouar B, Abdelaziz G, Aazza S, Gago C, Miguel MG (2013). Antioxidant activities of eight Algerian plant extracts and two Essentials oils. Industrial Crops and Products, 46: 85-96.

4. Caillet S and Lacroix M (2007). Essential oils: their antimicrobial properties and their potential application in food d'Ammoides verticillata (Nunkha). Rev, biology and health, 4(2): 1-10.

5. El Abed,D., N. Kambouche, Les huiles essentielles, 1ere Ed., Dar El Gharb, 2003.

6. El Ouariachi EM, Tomi P, Bouyanzer A, Hammouti B, Desjobert JM, Costa J, Paolini J (2011). Chemical composition and antioxidant activity of essential oils and solvent extracts of Ptychotis verticillata from Morocco. Food and Chemical Toxicology, 49: 533-536.

7. Harborne JB (1983). Phytochemical methods; A guide to modern Techniques of plant analysis. 3 rd edition Chapman and Hall. New York.

8. Kambouche N (2000). Extraction, Chemical Composition of the essential oil of Ajwain (Nounkha) in the region of Oran. Highlighting its biological activity, Magister, University of Oran, Algeria .

9. Merzougui I and Tadj H (2012). Study of the effect of antibacterial and antioxidant of Ammoides verticillata in the Tlemcen region, University of Tlemcen, Algeria.

10. Oumessaad T, Abdelghani D, Chérifa H (2011). Phytochemical study and antimicrobial activity 
of Ammoides verticillata, an Algerian endemic species. Curr. Opin. Bitechnol., 22, suppl 1, S143.

11. Tefiani C, Riazi A, Belbachir B, Lahmar H, Aazza S, Figueiredo AC, Miguel MG ( 2016). Ammoides pusilla (Brot.) Breistr. from Algeria: Effect of harvesting place and plant part (leaves and flowers) on the essential oils chemical composition and antioxidant activity. Open Chem., 14: 343-350.
12. Toubal O, Djahoudi A, Henchiri C, Bouazza M (2012). Phytochemical Screening and Antimicrobial Evaluation of the Aqueous Extracts of Ammoides verticillata, an Endemic Species. Journal of Life Science 6: 243-247.

13. Valnet J (2010). Aromatherapy: treatment of disease by the essences of plants. Maloine Ed. SA, $n^{\circ} 10,1984$. 